\title{
HIV/AIDS: The Major Demographic Challenge of Namibia
}

\author{
RIIKKA SHEMEIKKA, M.Sc. \\ Research Scholar, International Institute for Applied Systems Analysis (IIASA) \\ Laxenburg, Austria, and \\ Researcher, Population Research Unit, Department of Sociology \\ University of Helsinki, Finland
}

\section{Abstract}

In Namibia, as in many other countries in Southern Africa, the prevalence of HIV/AIDS has been growing rapidly during the 1990s. According to the HIV Sentinel Surveillance $1996,15.4 \%$ of pregnant women seeking prenatal care were HIV positive, and the highest HIV prevalence was found in the densely populated northern part of the country. The reports of the Health Information System of the Ministry of Health and Social Services show that there were 18,000 positive HIV tests during 1995-1996, and that AIDS has become the leading cause of death among reported deaths.

This paper is based on preliminary results of the research project Evaluating Alternative Paths for Sustainable Development in Namibia, Botswana and Mozambique, a project still continuing at the International Institute for Applied Systems Analysis (IIASA), Laxemburg, Austria. Multi-state population projections presented here include information on educational level and HIVIAIDS status of the population. Data used for the starting population of 1991 and the first five-year period, 1991-1996, is from: the 1991 Population and Housing Census, preliminary results of the 1996 Demographic Sample Survey, and the HIV-prevalence of women seeking antenatal care, based on National HIV Sentinel Surveys 1992-1997. Estimations for fertility and mortality in 1991 are based partly on published census results and partly on calculations made from the census tables. These calculations were made using indirect demographic estimation techniques, i.e. the Brass $P / F$ ratio method and Trussel's variant of the Brass method for the estimation of child mortality from information on children ever born and children surviving. In order to reduce the urban/rural bias of HIV sentinel survey sites, the results were weighted by the agespecific rural and urban populations, which somewhat lowers the national, average HIVprevalence compared with the results published earlier. The population projections were made using the PDEPROJ Software - software designed by IIASA for making multi-state population projections. In addition to being divided by sex and by five-year age groups, the population was divided into categories by educational level (low and high), and HIVI 
AIDS status (HIV negative, HIV positive, AIDS). These categories are combined into six states (e.g. HIV-negative population with low education, HIV-positive population with low education, population with AIDS and low education etc.). The scenario presented in this paper is only one example of possible future population development. In this scenario, fertility is assumed to decline to around three, mortality - excluding HIV/AIDS mortality - is assumed to remain stable and HIV prevalence is assumed to continue to grow as it has done during the 1990s. In order to show the magnitude of the impact of the HIV/AIDS epidemic in population development, a hypothetical scenario without any HIV/AIDS is also presented.

The results show that HIVIAIDS will have a significant effect on future population size and age structure. In case the current development continues, the population of Namibia will be over 836,000 smaller in 2026 than without HIV/AIDS. There will also be a remarkable impact on the age structure of the population.

Keywords: Namibia, population, population projections, fertility, mortality, HIV/AIDS

\section{Introduction}

Namibia's population was 1.6 million in 1996 and the average population density was 1.9 persons per $\mathrm{km}^{2}$. The population is very unevenly distributed; however, and $60 \%$ of the population lives in the northern part of the country, in a region that represents only $14 \%$ of the country's total land area. Almost $30 \%$ of the population was living in urban areas in 1991 . The age structure of Namibia is young $-42 \%$ of the population was under 15 years of age in 1991. The most commonly spoken language is Oshiwambo, which is spoken at home by $51 \%$ of the country's population. Population growth has been rapid in past decades; during 198191 it was over $3 \%$ per year. According to the 1991 census, the total fertility rate (TFR) was 6.1 and has been declining during the 1990s. Life expectancy at birth was estimated to be 59 years for men and almost 63 years for women in 1991. Migration, especially to urban areas, has been fast during independence. (RoN 1992; RoN 1994a; RoN 1994b.)

HIV/AIDS has become the greatest demographic challenge for Namibia, as for most of the countries in Southern Africa. It seems likely that the rapid population growth of past decades will be slowed down or perhaps even be halted by the fast-spreading epidemic. The current state of affairs requires strong new efforts and approaches from the organizations that collect information, formulate political responses, and study the impacts of the epidemic.

This paper is based on preliminary results of a research project entitled Evaluating Alternative Paths for Sustainable Development in Namibia, Botswana and Mozambique by the International Institute for Applied Systems Analysis (IIASA). ) (Shemeikka \& Noymer 1998). The aim of the paper is to estimate the impact of the HIV/AIDS epidemic on the population development of Namibia. As an example of the results of the project, two population projections are presented in this paper: an HIV/AIDS scenario, showing the population development, provided that the development of the epidemic continues the way it did in 1992-1996, 
and a hypothetical scenario of population development without any impact of HIV/AIDS on population. In both scenarios, all other assumptions are similar. Neither of these two scenarios can be seen as actual population forecasts; their purpose is more to illustrate the possible magnitude of the impact of the HIV/AIDS epidemic on population in the future, provided that the current development continues and that the other assumptions about fertility and mortality are fulfilled. This paper first describes the state of the HIV/AIDS epidemic in Namibia, both compared with the neighboring countries and within the different regions of the country itself. The second part of the paper presents population projections with and without the impact of HIV/AIDS and discusses the possible consequences of the HIV/AIDS epidemic on an individual and national level.

\section{HIV/AIDS in Namibia and several other Southern African countries}

UNAIDS and WHO have been reporting on the high HIV/AIDS prevalence in sub-Saharan Africa. They estimate that by the end of $1998,22.5$ million people will be living with HIV/ AIDS in sub-Saharan Africa and 33.4 million world-wide. Of all the new infections in the world in 1998, 70\% occurred in sub-Saharan Africa, and HIV prevalence among the 15-49year-old population was estimated to be $8 \%$. During the 1990 s, the epidemic has shifted southwards within sub-Saharan Africa; Namibia, among other countries in Southern Africa, has experienced very rapid growth in HIV/AIDS prevalence during this decade. (UNAIDS \& WHO 1998a; UNAIDS \& WHO 1998b)

HIV prevalence is very high in Namibia and almost all of the neighboring countries, i.e. Angola, Zambia, Zimbabwe, Botswana and South Africa. Prevalence is highest in Botswana and Zimbabwe and lowest in Angola. Among pregnant women in major urban centers the highest HIV prevalence was found in Botswana, 38.5\% in 1997, and the lowest in Angola, 1.5\% in 1995. UNAIDS estimated that at the end of 1997, HIV prevalence among the 15-49-year-old population, male and female combined, was above $25 \%$ in Botswana and Zimbabwe and between $10-20 \%$ in all the other above- mentioned countries, except for Angola, where it was estimated to be only $2 \%$. (RoB 1997; UNAIDS \& WHO 1998a.)

Altogether, UNAIDS estimated that there were 6.6 million people, both adults and children, living with HIV/AIDS in the afore-mentioned countries by the end of 1997. The main mode of transmission in Southern Africa, as in sub-Saharan Africa in general, is heterosexual intercourse. In Angola, a relatively high proportion of transmissions occurred via blood and blood products, i.e. $24 \%$ of reported AIDS cases, and also via drug needles, i.e. $9 \%$ of reported AIDS cases. In Zambia, blood and blood products accounted for $5 \%$ of reported AIDS cases, and in South Africa, homosexual contact between men accounted for $7 \%$ of reported AIDS cases. Unfortunately, there is no data on the modes of transmission in Namibia. UNAIDS estimates vertical transmission to be $35 \%$ in sub-Saharan Africa; i.e. $35 \%$ of the babies born to HIV-infected mothers will be infected with HIV/AIDS. (UNAIDS \& WHO 1998a.) 


\section{The state of the HIV/AIDS epidemic in Namibia}

Estimations of the HIV/AIDS epidemic in Namibia are mainly based on HIV sentinel surveillance of pregnant women seeking prenatal care, and on monthly reports of the Health Information System (HIS) by the Ministry of Health and Social Services. In addition, HIV infections of potential blood donors and STD patients provide some information on the state of the epidemic. Unfortunately, all this data is very restricted in the background variables available. In HIV Sentinel Surveillance data, only information on age and sentinel site of women is available. In the HIS reports, information is mostly restricted to region, omitting the sex and age of the HIV/AIDS cases. Providing additional background information e.g. on education or marital status, and in the HIS reports, on sex and age, would be very useful for understanding the epidemic.

The first HIV/AIDS case in Namibia was reported in 1986. Both HIV sentinel surveillance data and health reports indicate that HIV/AIDS has been spreading fast during the 1990s. UNAIDS estimated that there were 150,000 people in Namibia, both adults and children, living with HIV/AIDS by the end of 1997, and that 14,000 AIDS deaths have occurred since the beginning of the epidemic. (RoN 1996; UNAIDS \& WHO 1998a; UNDP 1997).

\section{HIV sentinel surveillance data}

HIV sentinel surveillance is a national sero-survey of antenatal care users. Pregnant mothers are considered a good indicator group for the sexually active population. About $80 \%$ of women in Namibia are using antenatal services. The surveillance was conducted among pregnant women seeking antenatal care at five sentinel sites in 1992, at ten sentinel sites in both 1994 and 1996, and at four sentinel sites in 1997. The surveillance took place as anonymous screening of blood samples of women who used antenatal services. The sentinel sites, hospitals and clinics were selected with consideration given to the geographical distribution of the population, the urban/rural division of population and a sufficient number of first-visit antenatal care seekers. Seven out of ten sites were located in the northern part of the country, where more than $60 \%$ of the population lives. Six sites were located in urban and four in rural areas. During the 8-week survey period, all the women who visited an antenatal clinic for the first time during the current pregnancy were selected. The requested sample size per sentinel site was 250 . Blood samples originally collected for other purposes were labeled by the code of the sentinel site and the age of the woman; all the identifying information was removed. Samples were forwarded to the Central Laboratory at Windhoek, where they were tested for HIV antibodies. All the samples were tested by a highly sensitive first line ELISA ${ }^{1}$ (HIV 1+2, 3 rd generation including subtype 0 ). Non-reactive samples were recorded as negative, and reactive samples were tested by a highly specific ELISA $($ HIV1+2). Samples positive on both ELISAs were recorded as positive.

Based on results of the tests, the Case Management and Surveillance Unit at the National AIDS Control Programme performed the data entry and analysis. HIV-point prevalence rates

'Enzyme-Linked ImmunoSorbent Assay test used to detect specific antibodies in the blood. 
with $90 \%$ confidence intervals were calculated for each sentinel site. Cases with the age unknown were distributed according to the age structure of the sentinel site. Age distribution of the women included in the survey was compared with that of all women giving birth and that of women testing for HIV in the survey.

In 1996, 1,854 blood specimens were received. The requested sample size of 250 was achieved at two sentinel sites (Windhoek and Oshakati). The smallest sample size was provided by Andara, with only 86 samples. The rest of the sentinel sites provided sample sizes between 132 and 249. Age was missing in 25 specimens. The mean age of HIV-positive women did not differ from the mean age of HIV-negative women. The age distribution of women included in the survey and that of those who were HIV-positive resembled the age structure of all women giving birth during the January - August 1996, indicating that the sample is representative of pregnant women as far as age is concerned.

According to the results, HIV prevalence is highest among women aged 20-34 years (Figure 1). In 1996, the proportion of HIV-positive women was $17.6 \%$ in urban areas and $10.4 \%$ in rural areas. (RoN 1996.)

Figure 1. Age-specific HIV prevalence in pregnant women, 1994 and 1996. Source: RoN 1996.

\section{HIV Prevalence \%}

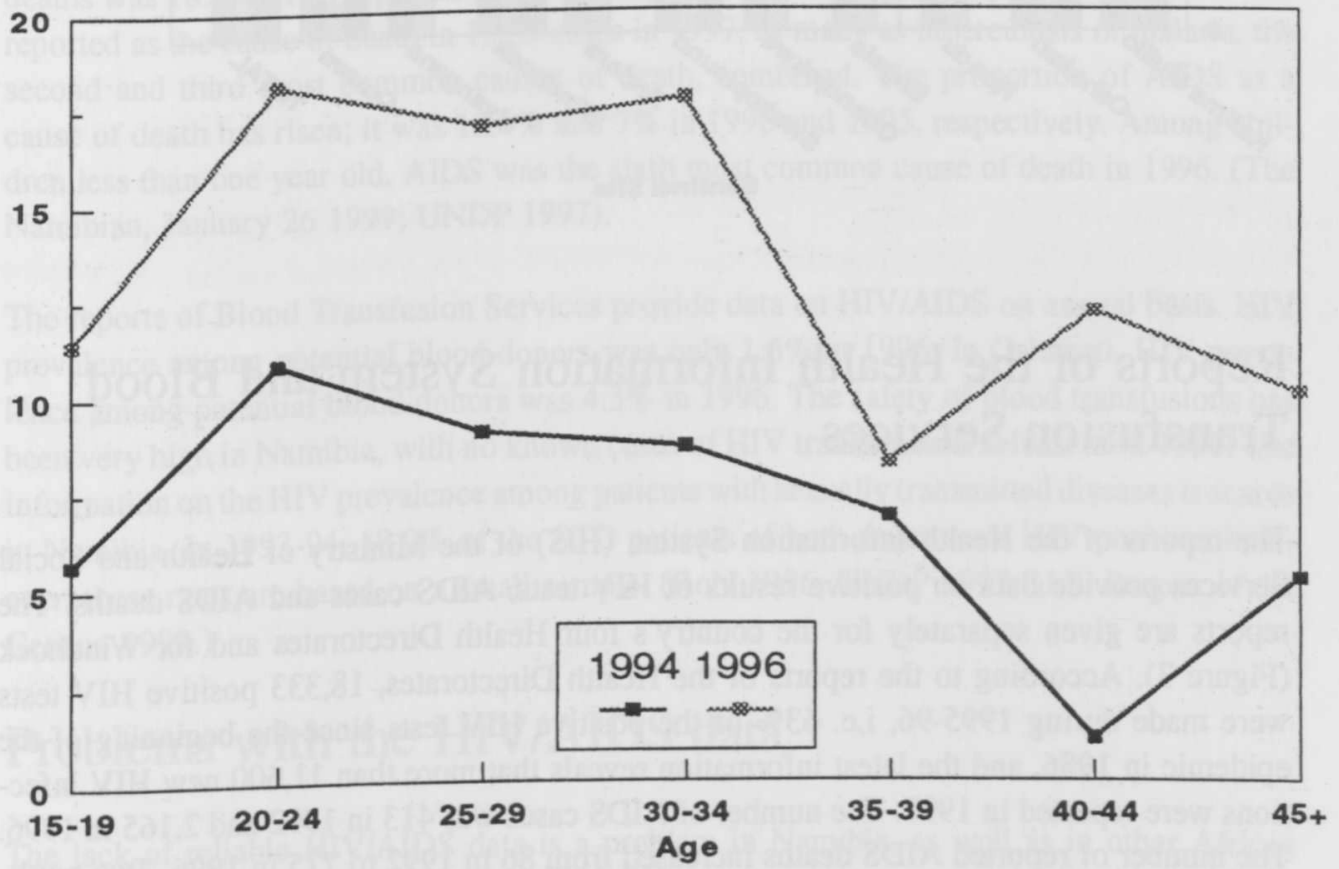

The proportion of all HIV-positive women increased from $4.2 \%$ in 1992 to $15.4 \%$ in 1996 (Figure 2). The regional differences between the sentinel sites are significant, and HIV is most widely spread in the densely populated northern regions. The highest HIV prevalence is found in Katima Mulilo, an urban center located on the Caprivi strip, where the prevalence was above $20 \%$ already in 1994 . In 1997 , HIV prevalence among pregnant women in Katima 
Mulilo was $25.5 \%$. In Oshakati, another northern urban center, $22.4 \%$ of pregnant women were HIV positive in 1996. HIV prevalence in Windhoek, the capital city, was $16 \%$ in 1996. (RoN 1996; Webb \& Simon 1995.)

Figure 2. HIV prevalence among pregnant women by sentinel site, 1992-1997. Note: Some of the sentinel sites were excluded from the surveillance in 1992 and 1997. Source: RoN 1995;RoN 1996.

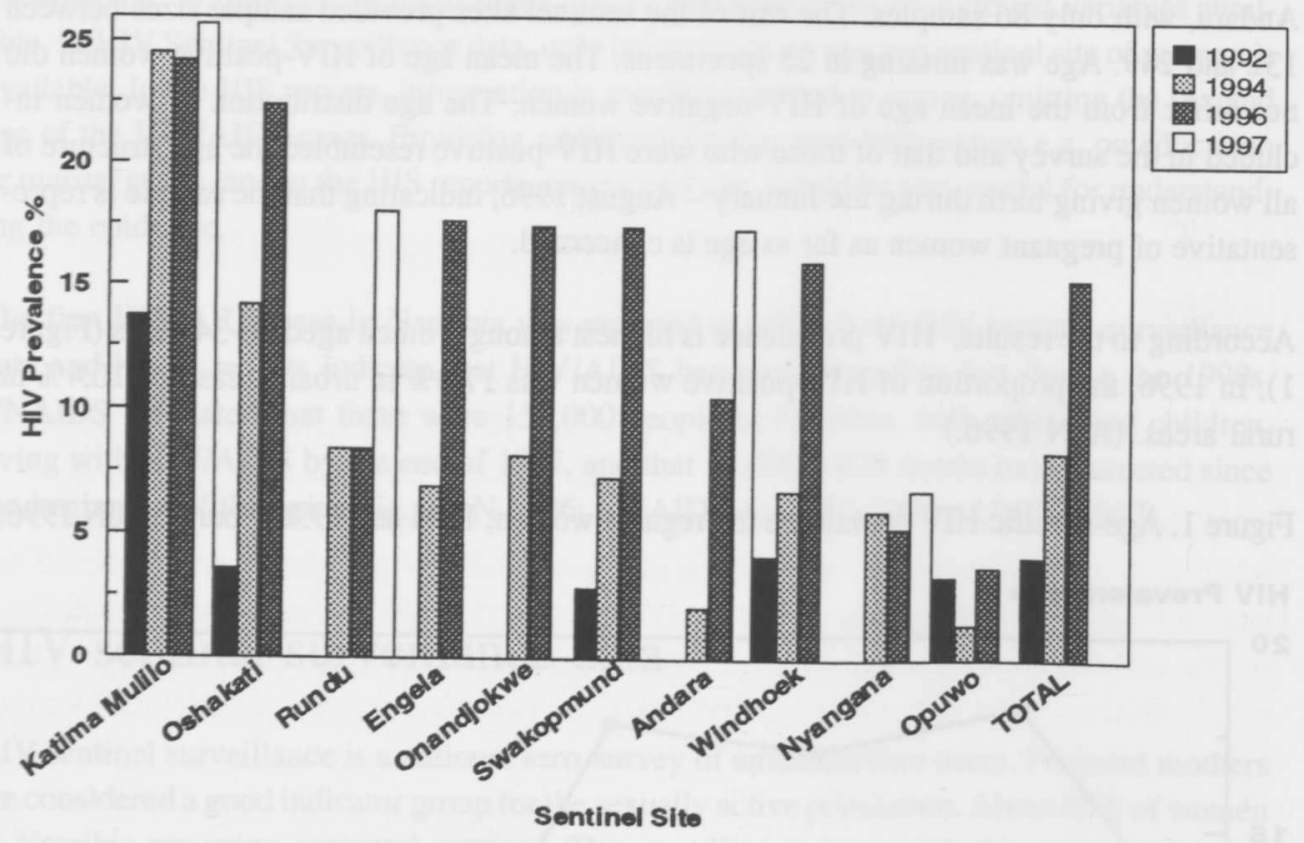

\section{Reports of the Health Information System and Blood Transfusion Services}

The reports of the Health Information System (HIS) of the Ministry of Health and Social Services provide data on positive results of HIV tests, AIDS cases and AIDS deaths. The reports are given separately for the country's four Health Directorates and for Windhoek (Figure 3). According to the reports of the Health Directorates, 18,333 positive HIV tests were made during $1995-96$, i.e. $63 \%$ of the positive HIV tests since the beginning of the epidemic in 1986, and the latest information reveals that more than 11,600 new HIV infections were reported in 1997. The number of AIDS cases was 413 in 1992 and 2,165 in 1996. The number of reported AIDS deaths increased from 86 in 1992 to 775 in 1996. Two northern Health Directorates, the North East and the North West, accounted for $41 \%$ of the positive HIV tests, $72 \%$ of the reported AIDS cases, and $84 \%$ of the reported AIDS deaths in 1996. $60 \%$ of the total population of the country lived in this region in 1991. Also, the highest proportions of reported new AIDS cases per 100,000 of the population are found in northern regions and in the region where the capital city, Windhoek, is located.(The Namibian, January 26 1999; RoN 1996; UNDP 1997). 
Figure 3. Reported AIDS cases by Health Directorate, 1996. Source: UNDP 1997.

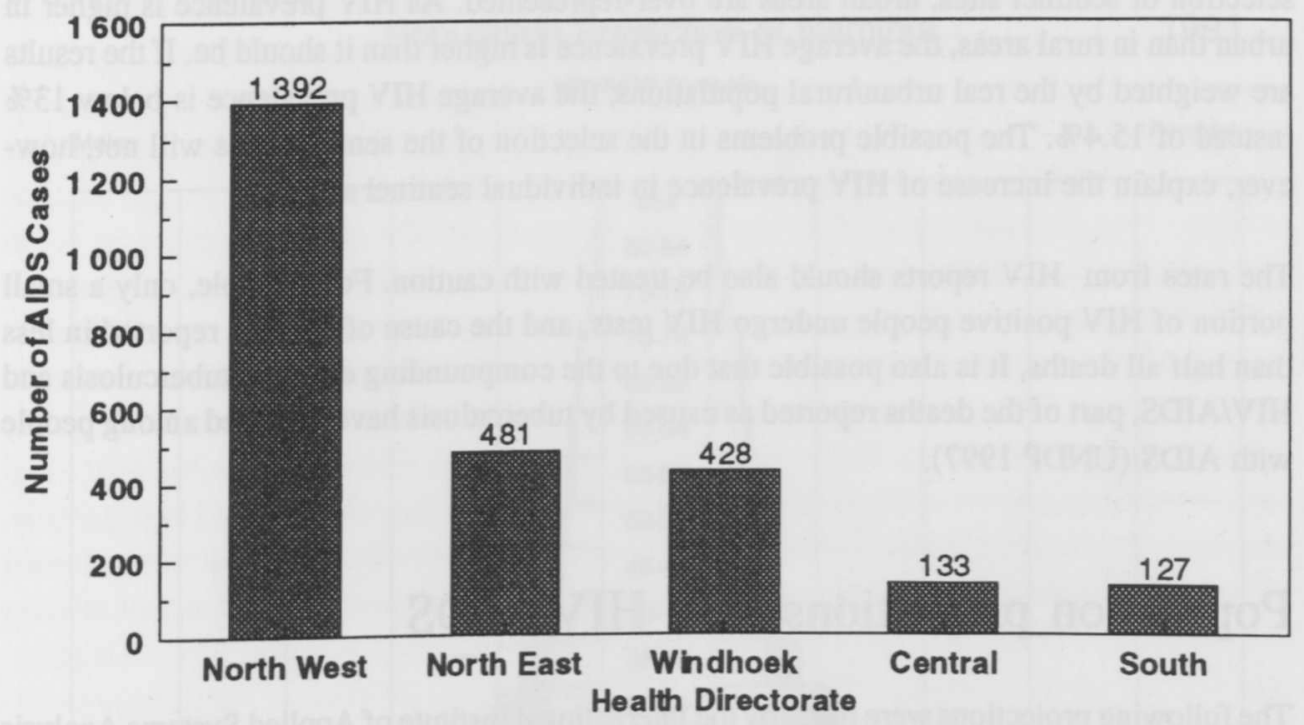

AIDS has become the most common cause of death in Namibia. The proportion of AIDS deaths was $18.6 \%$ of all reported deaths among persons of all age groups in 1997. AIDS was reported as the cause of death in 1,539 cases in 1997, as many as tuberculosis or malaria, the second and third most common causes of death, combined. The proportion of AIDS as a cause of death has risen; it was $12.4 \%$ and $7 \%$ in 1996 and 1995, respectively. Among children less than one year old, AIDS was the sixth most common cause of death in 1996. (The Namibian, January 26 1999; UNDP 1997).

The reports of Blood Transfusion Services provide data on HIV/AIDS on annual basis. HIV prevalence among potential blood donors was only $1.6 \%$ in 1996. In Oshakati, HIV prevalence among potential blood donors was $4.3 \%$ in 1996. The safety of blood transfusions has been very high in Namibia, with no known cases of HIV transmission at least until 1996. The information on the HIV prevalence among patients with sexually transmitted diseases is scarce in Namibia. In 1993-94, 18.2\% of the STD patients of both sexes were HIV positive; however, these rates are based on a small sample. (RoN 1996; UNDP 1997; U.S. Bureau of the Census 1998.)

\section{Problems with the HIV/AIDS data}

The lack of reliable HIV/AIDS data is a problem in Namibia, as well as in other African countries. HIV sentinel surveys of pregnant women has been estimated to be one of the most reliable sources of information. Other possible sources are for instance the reports of the health officials and the HIV tests of blood donors. All the data sets available are missing important background variables-for instance, HIV sentinel data does not contain information on education, employment or marital status of the respondent, and the HIS report data is lacking even the age and sex of the HIV/AIDS cases. 
The selection of the sentinel sites may also have an impact on the results. In the current selection of sentinel sites, urban areas are over-represented. As HIV prevalence is higher in urban than in rural areas, the average HIV prevalence is higher than it should be. If the results are weighted by the real urban/rural populations, the average HIV prevalence is below $13 \%$ instead of $15.4 \%$. The possible problems in the selection of the sentinel sites will not, however, explain the increase of HIV prevalence in individual sentinel sites.

The rates from HIV reports should also be treated with caution. For example, only a small portion of HIV positive people undergo HIV tests, and the cause of death is reported in less than half all deaths. It is also possible that due to the compounding effect of tuberculosis and HIV/AIDS, part of the deaths reported as caused by tuberculosis have occurred among people with AIDS (UNDP 1997).

\section{Population projections with HIV/AIDS}

The following projections were made by the International Institute of Applied Systems Analysis as a part of a research project entitled Evaluating Alternative Paths for Sustainable Development in Namibia, Botswana and Mozambique, by the author and Mr. Andrew Noymer (Shemeikka \& Noymer 1998).

These population projections are so-called multistate population projections, where the population is divided into subgroups by education and HIV/AIDS status. Multistate population projections by education have their advantages: vital rates, like fertility and mortality, vary according to education. These variations, their changes and changes in the educational structure of the population can be taken into consideration while making multistate population projections with education. In addition to education, some other characteristics can be included into population projections. In earlier research projects by IIASA, for instance, employment status has been used as an additional state in multistate population projections. For countries in Southern Africa, the HIV/AIDS epidemic will have a significant impact on population development. Therefore, both education and HIV/AIDS status have been included as states in these projections.

There are two educational categories in the following population projections. The low education group consists of the part of the population with no formal education and the population with primary education, whereas the high education group consists of the part of the population with secondary and higher education. For HIV/AIDS status there are three categories: HIV negative, HIV positive and AIDS. These categories are combined into six interacting states: low education and HIV-negative population, low education and HIV-positive population, low education population with AIDS, high education and HIV-negative population, high education and HIV-positive population, and high education population with AIDS. The assumptions for fertility and mortality vary for each of the afore-mentioned sub-populations. Projections are made using five-year age groups and five-year time periods. 
Figure 4. Starting population for the population projections: Population of Namibia in 1991.

$$
\begin{aligned}
& \text { Population Projection of Namibia } \\
& \text { HIVIAIDS Scenario }
\end{aligned}
$$

Males

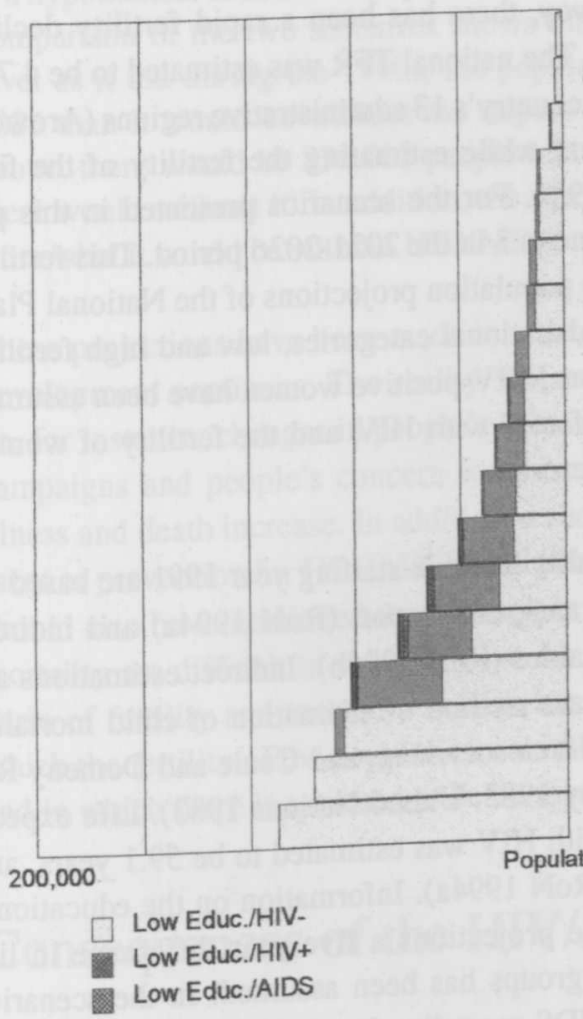

Females

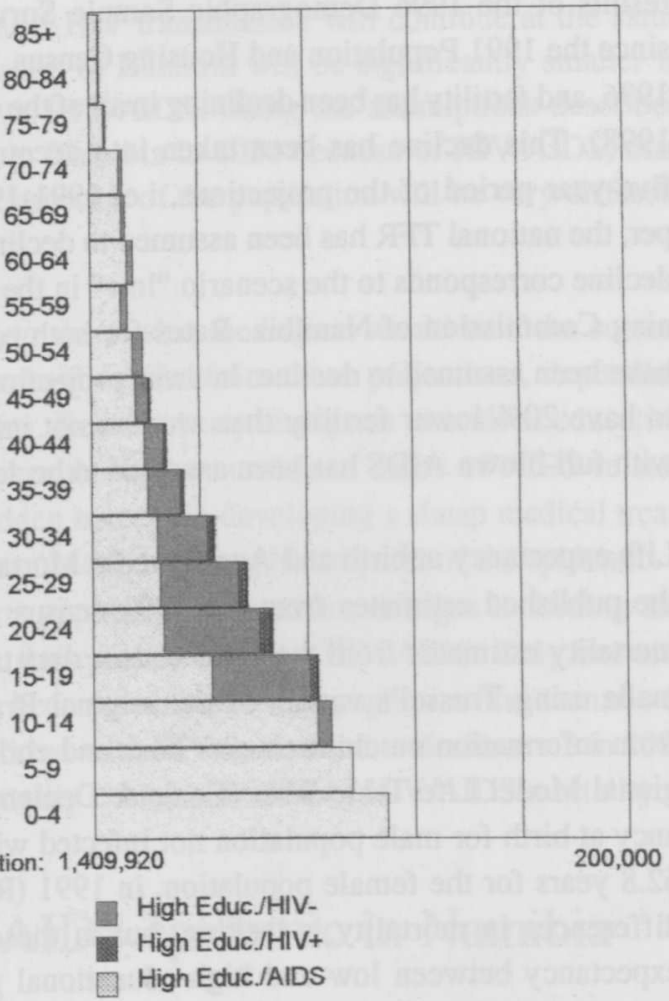

\section{Data, methods and assumptions}

Data for the starting year 1991 (Figure 4) has been obtained from the 1991 Population and Housing Census (RoN 1994b). In the following population projections, it has been assumed that there will be a decline in fertility both among women who are not infected with HIV/ AIDS and among HIV-positive women. Mortality, with the exception of AIDS mortality, is assumed to remain stable. Values for mortality and fertility are based partly on the published rates of the 1991 census analytical report (RoN 1994a), and partly on calculations made from aggregated census data tables (RoN 1993b; RoN 1994b) using indirect methods for estimations of fertility and mortality.

In the 1991 census analytical report, the Total Fertility Rate (TFR) of Namibia was estimated to be 6.1 children per woman. There are significant differences in fertility according to the educational level of the women. TFR for women with no education is 8.8 , for those who completed grade six it is 7.2 , for those who completed grade nine it is 4.2 , and for those who completed grade 12 it is 3.1 (RoN 1994a). These educational rates were used for 
population projections, modified for the two educational categories, "low education" and "high education." The age structure of fertility, i.e. the Age-Specific Fertility Rates, were calculated from the 1991 census data tables (RoN 1994b). Fertility estimates have been made using the Brass method, based on comparison of period fertility rates with reported average parities, i.e. the P/F ratio method (United Nations 1983). According to the first results of the 1996 Demographic Sample Survey, there has been a rapid fertility decline since the 1991 Population and Housing Census. The national TFR was estimated to be 4.7 in 1996, and fertility has been declining in all of the country's 13 administrative regions (Arowolo 1998). This decline has been taken into account while estimating the fertility of the first five-year period of the projections, i.e. 1991-1996. For the scenarios presented in this paper, the national TFR has been assumed to decline to 3 in the 2021-2026 period. This fertility
decline corresponds to the scenario "low" in the population projection ning Commission of Name corresponds to the scenario "low" in the population projections of the National Planhave been assumed to decline. In these projections, HIV categories, low and high fertility, to have $20 \%$ lower fertility than women not infected with HIV, and the fertility of women with full-blown AIDS has been assumed to be zero.

Life expectancy at birth and Age-Specific Mortality Rates in starting year 1991 are based on the published estimates from the 1991 census analytical report (RoN 1994a) and indirect mortality estimates from the 1991 census data tables (RoN 1994b). Indirect estimations are made using Trussel's variant of the original Brass method of estimation of child mortality from information on children ever born and children surviving, and Coale and Demeny Regional Model Life Table West (Coale \& Demeny 1983; United Nations 1983). Life expectancy at birth for male population not infected with HIV was estimated to be 59.1 years, and 62.8 years for the female population, in 1991 (RoN 1994a). Information on the educational differences in mortality is lacking, but in these projections a five-year difference in life presented in this paper, mortality, excluding AIDS mortality, has been stable during the projected time period.

Estimations of age-specific HIV and AIDS prevalence in the starting population of 1991 and in the first five-year period 1991-1996 are based on the published data of the sentinel surveys of 1992, 1994 and 1996 (RoN 1995; RoN 1996). As the urban population was overrepresented in the selection of sentinel sites, the age-specific HIV prevalences are weighted with the real urban and rural populations. This somewhat lowers the national HIV prevalence.
For instance, in 1996 the national average of HIV prevalence among pregnat $15.4 \%$ without weighting and below $13 \%$ when weighted with urban/rural population. was fortunately, the information provided by sentinel surveys is very restricted. Therefore, the following assumptions have been made for the scenarios presented in this paper: HIV prevalence of men is assumed to be $80 \%$ of that of women in the same age group; HIV prevalence of the low education group is assumed to be $80 \%$ of the national average, and that of the high educational group to be $120 \%$ of the national average; vertical transmission (mother-to-child transmission) is assumed to be $35 \%$. In addition, HIV infection is assumed to develop into children, these developments are assumed to occur faster. 


\section{Results}

Results of two scenarios are presented in figures 5 and 6 . In the first case, it is assumed that HIV/AIDS continues spreading until 2026 as it did between 1992-1996. The second scenario is a hypothetical scenario of population development without any HIV/AIDS in Namibia. The comparison of the two scenarios shows that if HIV transmission will continue at the same level as it did during the 1990s, the population of Namibia will be significantly smaller in 2026 than it would be without the impact of HIV/AIDS. Using the assumptions described above, there would be 836,000 people less in Namibia in 2026 because of HIV/AIDS, than there would without it. In addition, the age structure of the population will be very different from what it would be without HIV/AIDS.

These projections have been made in order to show what the impact would be if the current development continues. The reality will probably differ from these projections, depending on, for instance, changes in people's behavior. Behavior may change as a result of education campaigns and people's concern for their health, as the number of cases of AIDS-related illness and death increase. In addition, a sudden success in developing a cheap medical treatment or prevention for HIV/AIDS would change the demographic impacts of the epidemic. It should also be remembered that in long-term population projections, changes in fertility and mortality are difficult to estimate even for those not infected by HIV/AIDS. Only one scenario of fertility and mortality decline has been presented in this paper, i.e. the scenario in which the fertility of the population not infected with HIV is assumed to decline to 3 in 2026 and in which there is assumed to be no mortality changes, excluding HIV/AIDS mortality.

\section{Consequences of the HIV/AIDS epidemic in Namibia}

Namibia, like other Southern African countries, has faced a rapid worsening of the HIV/AIDS epidemic during the 1990s. This epidemic will most probably have a strong impact on the demographic development of Namibia. It will slow down the population growth by affecting both mortality and fertility. Because of AIDS, mortality among both the female and male working-age population will increase. Child mortality will increase because of vertical transmission of HIV/AIDS from HIV-positive mothers to their children. The fertility of HIVpositive women and women with AIDS is lower than that of women with no HIV infection. In addition, increased mortality among women of reproductive age will decrease their number, and therefore also the potential number of children to be born. HIV/AIDS will probably also affect population in less direct ways. For instance, the mortality of AIDS orphans will probably be higher than that of children whose mothers are alive. In addition to the size of the population, HIV/AIDS will also change its future age structure.

HIV/AIDS will have an effect on many different levels. Disease and death will cause physical and psychological suffering for the people infected and their families, together with economic disturbances. AIDS orphans and elderly people will suffer when the economic support from the working-age population is diminished. Possible discrimination of infected people in work places and social life will also cause problems on an individual level. On the national 
Figure 5. Population of Namibia in 2026 with the impact of HIV/AIDS.

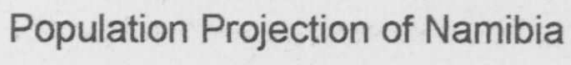

HIVIAIDS Scenario

Males
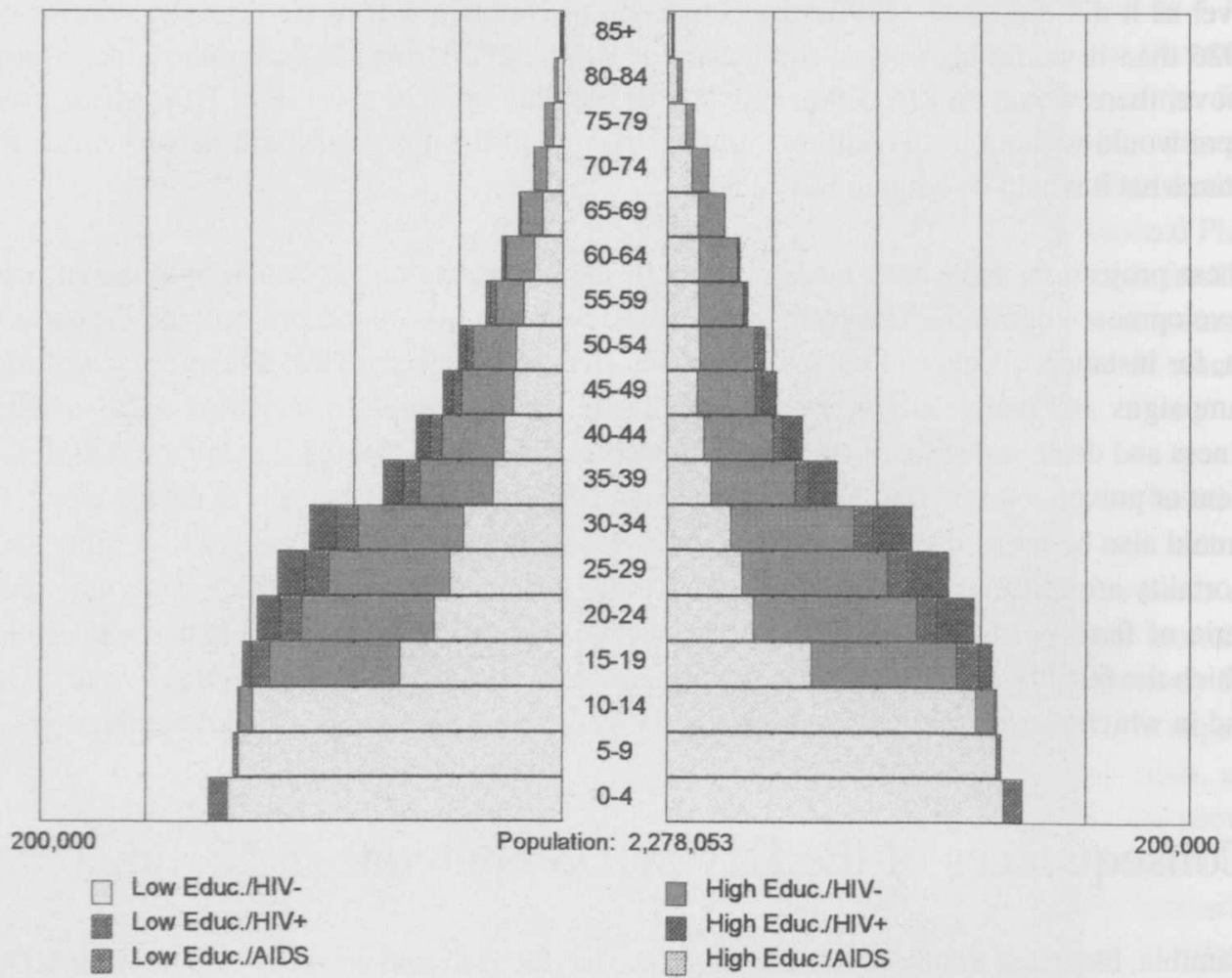

level, economic problems will be caused by e.g. increasing needs for investments in health care. In addition, increasing morbidity and mortality will cause economic losses in human resources and labor productivity. UNDP Namibia estimates that direct and indirect costs caused by HIV/AIDS will amount to $20 \%$ of the GDP by 2001 , compared to $3.2 \%$ in 1996 . These costs consist of e.g. medical costs, proposed disability allowances to people with AIDS, and the value of lost productive years (The Namibian, 26 January 1999).

The volume of impacts of the HIV/AIDS epidemic will depend on changes in reproductive behavior and on the developments in medical science. There are some encouraging experiences, of powerful information campaigns, training, and reproductive health services in some other countries in sub-Saharan Africa, e.g. in Senegal (UNAIDS \& WHO 1998a). Also in Namibia, there are some signs of positive development in reproductive behavior. 
Figure 6. Population of Namibia in 2026 without the impact of HIV/AIDS.

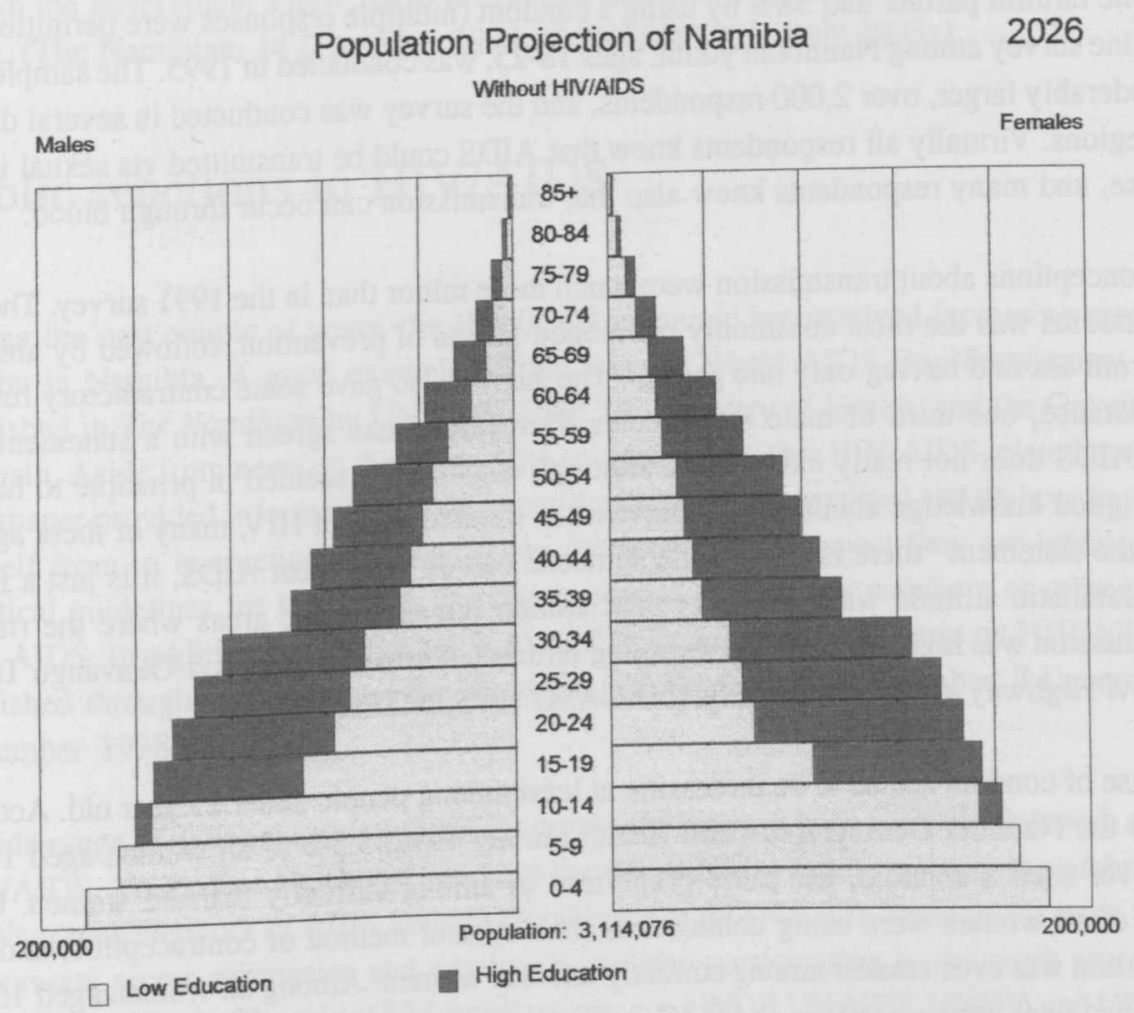

\section{Changes in HIV/AIDS awareness and condom use}

Information on the awareness concerning HIV/AIDS in Namibia is restricted to small sample surveys and should therefore be treated with caution. It seems likely that knowledge of HIV/ AIDS and the ways of transmitting HIV have increased during the 1990s. The 1991 National AIDS Awareness Survey was conducted among a small sample of the adult population in several locations throughout the country. According to the survey, $90 \%$ of the population said they had heard about AIDS, and that the main source of information was radio. $81 \%$ of those who had heard about AIDS knew that it is transmitted through sexual intercourse, and $56 \%$ knew that infected blood can also be a means of transmission. The most common misconceptions were that transmission can occur via kissing $(16 \%)$ or through mosquitoes $(17 \%)$. Other misconceptions about transmission, such as the virus being transmitted through touching, sharing a glass or shaking hands with someone were also relatively common (17\%) (multiple responses were permitted). $79 \%$ of respondents said that there is no cure for AIDS, and 
$73 \%$ knew that the disease can be prevented. Out of those who answered that AIDS can be prevented, $64 \%$ said that it can be prevented by not having sex with strangers, $67 \%$ by keeping one faithful partner and $38 \%$ by using a condom (multiple responses were permitted). A baseline survey among Namibian youth, ages 18-25, was conducted in 1995 . The sample was considerably larger, over 2,000 respondents, and the survey was conducted in several different regions. Virtually all respondents knew that AIDS could be transmitted via sexual intercourse, and many respondents knew also that transmission can occur through blood.

Misconceptions about transmission were much more minor than in the 1991 survey. The use of condoms was the most commonly mentioned means of prevention, followed by abstaining from sex and having only one partner. The survey also gave some contradictory results, for instance, one third of male respondents from rural areas agreed with a statement that HIV/AIDS does not really exist. Also, although respondents seemed in principle to have a fairly good knowledge about how to prevent the transmission of HIV, many of them agreed with the statement "there is really little someone can do to prevent AIDS, it is just a fate." This fatalistic attitude was most prevalent among females in the areas where the risk of transmission was high, $80 \%$ and $85 \%$ among females in urban and Caprivi-Okavango TransCaprivi Highway areas, respectively. (NANASO 1995; NISER 1991.)

The use of condom seems to be increasing at least among people under 25 year old. According to the Namibia Demographic and Health Survey 1992, 5.5\% of all women aged 15-49 had ever used a condom, the same proportion as among currently married women. Only $0.5 \%$ of all women were using condoms as their current method of contraception, and this proportion was even smaller among currently married women. Among all women aged 15-19, $2.4 \%$ had ever used a condom and $0.3 \%$ were using it as their current method of contraception. These proportions were slightly higher among 20-24-year-old women. $7.4 \%$ of them had ever used a condom and $0.9 \%$ were using it as their current method of contraception.

There was no significant difference in the use of condoms as the current contraceptive method between women who lived urban and those who lived in rural areas in 1992. Among currently married women, ages $15-49$, the prevalence of condom use was $0.5 \%$ and $0.1 \%$ in urban and rural areas, respectively. According to the Namibian Youth Baseline Survey 1995, conducted among the 18-25-year-old population, the proportion of those using condoms was considerably higher. Among young women, the proportion who had ever used condoms varied from $52 \%$ to $32 \%$ in urban and rural areas, respectively. For male respondents, proportions varied from $81 \%$ in urban to $51 \%$ in rural areas. The proportion of urban males who used a condom during their last sexual intercourse with a casual partner was $88 \%$ and the proportion of urban males who had used a condom during their last intercourse with a regular partner was $45 \%$. Among urban females, $84 \%$ had used a condom with their last casual partner and $54 \%$ during their last intercourse with a regular partner.

In 1992, the educational level of a woman did not make a significant difference in the use of condoms as a current contraceptive method; it was below $1 \%$ in all educational groups. Educational differences in condom use may have changed during the $1990 \mathrm{~s}$; unfortunately there is no data available of the present-day situation. In 1999, a pilot project for promoting the 
use of female condoms, i.e. femidoms, will start in four of Namibia's 13 regions. This project is sponsored by private organizations and companies. Femidoms will probably play a part also in the government's new AIDS prevention initiatives which will be announced in early 1999. (The Namibian, 14 December 1998; NANASO 1995; RoN 1993a).

\section{Public reactions to HIV/AIDS}

During the past couple of years, the HIV/AIDS epidemic has received increasing media attention in Namibia. A good example of this was the World AIDS Day Supplement 1998, published in The Namibian by UNAIDS, UNICEF, Ministry of Health, and the Government of Spain. Aside from news on the state of the epidemic and other HIV/AIDS related news, the newspaper provided information on the ways the disease is transmitted and on how to protect oneself from it, instructions on what to do for people who suspect they are infected, and practical guidelines for those who are taking care of sick family members or other people with AIDS. In addition to this special World AIDS Day Supplement, news on HIV/AIDS are published throughout the year. (The Namibian, 27 November; 2 December; 3 December; 4 December 1998.)

A wide range of national and international organizations have been active in the work against HIV/AIDS. Thirty-five NGOs are working for HIV/AIDS prevention under the umbrella of the Namibian Network of AIDS Service Organisations (NANASO). Some of the trade unions and private sector companies and employers are also participating in the work against the HIV/AIDS epidemic. The role of UN organizations, e.g. UNDP, UNAIDS, UNFPA and UNICEF, has been very active and important in both provoking public discussion on the topic and providing information on the state of the HIV/AIDS epidemic and its consequences. (The Namibian, 5 February 1999; UNDP 1997.)

The National AIDS Control Programme (NAPC) was launched within the Ministry of Health and Social Services (MHOSS) in 1990. A Short-Term Plan was made for the years 1990-92 and it was followed by the first Medium-Term Plan for the years 1992-1997. Some of the sectors other than the health sector have also responded to the HIV/AIDS epidemic. For instance, the guidelines for the implementation of the National Code on HIV/AIDS in Employment were published in July 1998. The HIV/AIDS code makes it illegal for an employer to test employees or prospective employees for HIV, or to use a person's HIV status to determine his/her job status, promotion or transfer. It also gives employees with HIV/AIDS the legal right to confidentiality about their HIV status in any aspect of employment. The Code of HIV/AIDS in employment was soon dismissed, however, by the Namibian Defence Forces. A comprehensive policy paper on higher education, tabled in September 1998 by Minister of Higher Education, Vocational Training, Science and Technology, emphasizes the role of the Ministry in information and education on HIV/AIDS. It also states that employees in the higher education sector who have tested positive for HIV/AIDS should be encouraged to continue working, and students should be encouraged to complete their studies, if possible. In some respects, the official reactions to the epidemic have been relatively slow. For 
instance, Namibia's national population policy document, accepted in 1997, HIV/AIDS was still only briefly mentioned among other diseases (RoN 1997). Also, the NAPC has been heavily criticized by NANASO and some other organizations that work against HIV/AIDS in Namibia. Currently, a new five-year Strategic Plan on HIV-AIDS Prevention and Control in Namibia, and the National AIDS Coordination Programme have been prepared by the Government. Both of them will be launched at the end of January 1999. (The Namibian, 28 July; 5 August; 10 August, 19 September; 27 October; 3 December 1998; 5 February 1999; UNDP 1997.)

\section{References}

Arowolo, O. O. 1998. Fertility in Namibia. Unpublished working paper for IIASA (International Institute for Applied Systems Analysis). Windhoek 1998.

RoB (= Republic of Botswana) 1997. Botswana HIV Sentinel Surveillance 1997. Gaborone, Botswana.

Coale, Ansley J. \& Paul Demeny. 1983. Regional Model Life Tables and Stable Populations. New York: Academic Press.

The Namibian. 28 July 1998; 5 August 1998; 10 August 1998; 19 September 1998; 27 October 1998; 27 November 1998; 2 December 1998; 3 December 1998; 4 December 1998; 14 December 1998; 26 January 1999; 5 February 1999; 4 December 1999.

NANASO (Namibian Network of AIDS Service Organizations) 1995. Sexual Knowledge, Attitudes and Practices Among Namibian Youth. A Baseline Survey. Windhoek.

NISER 1991. National AIDS Awareness Survey. Namibian Institute for Social and Economic Research, University of Namibia (NISER), Windhoek.

RoN (=Republic of Namibia) 1992. 1991 Population and Housing Census. Preliminary Report. National Planning Commission, Central Statistics Office, Windhoek.

RoN 1993a. Namibia Demographic and Health Survey 1992. Ministry of Health and Social Services and Demographic and Health Surveys Macro International Inc.

RoN 1993b. 1991 Population and Housing Census. Report A. Statistical Tables. Volumes IV. (Tables for 27 Census Districts). Central Statistics Office, National Planning Commission, Windhoek.

RoN 1994a. 1991 Population and Housing Census: Basic Analysis with Highlights. Central Statistics Office, National Planning Commission, Windhoek.

RoN 1994b. 1991 Population and Housing Census. Report B. Statistical Tables. (Tables for 13 Administrative Regions). Central Statistics Office, National Planning Commission, Windhoek.

RoN 1995. Epidemiological Information on HIV-Infection and AIDS in Namibia. Ministry of Health and Social Services, National AIDS Control Programme, HIV/AIDS/STD Case Management and Surveillance, December 1995. Windhoek.

RoN 1996. National HIV Sentinel Surveillance 1996. Ministry of Health and Social Services, National AIDS Control Programme, HIV/AIDS/STD Case Management \& Surveillance, October 1996. Windhoek 
RoN 1997. National Population Policy for Sustainable Human Development. National Planning Commission, Windhoek.

Shemeikka, Riikka \& Andrew Noymer.1998. Population projections for Namibia and Botswana. Unpublished working paper made for IIASA (International Institute for Applied Systems Analysis). Laxenburg 1998.

UNAIDS \& WHO 1998a. Global HIV/AIDS \& STD Surveillance. Report on the Global HIV/ AIDS epidemic - June 1998. (Published in the Internet.)

UNAIDS \& WHO 1998b. AIDS epidemic update: December 1998. (Published in the Internet.) UNDP 1997. Human Development Report 1997. The Impact of HIV and AIDS in Namibia. UNDP Namibia with UNAID Co-sponsors. Windhoek.

United Nations 1983. Manual X: Indirect Techniques for Demographic Estimation. Department of International Economic and Social Affairs. Population Studies 81. New York 1983.

U.S. Bureau of the Census 1998. HIV/AIDS Surveillance Data Base. January 1998.

Webb, Douglas \& David Simon.1995: Migrants, Money and the Military: The Social Epidemiology of HIV/AIDS in Owambo, Northern Namibia. NEPRU Occasional Paper 4, August 1995. Windhoek. 